\title{
The Pragmatic Values of Evidential Sentences
}

\author{
Christopher Davis, Christopher Potts, and Margaret Speas \\ UMass Amherst
}

\section{Semantic Values and Pragmatic Values}

Lewis (1986a: $\S 5)^{1}$ articulates and explores a trio of important general theses concerning pragmatic values:

$$
\begin{aligned}
& \text { Pragmatic values are } \\
& \text { i. irreducibly distinct from semantic denotations; } \\
& \text { ii. sometimes specific to individual clause types; and } \\
& \text { iii. appropriately modeled with probabilities. }
\end{aligned}
$$

Lewis $(1976,1986 b)$ concentrates on material conditionals, arguing that their semantic values are propositional but that their pragmatic values are given by conditional subjective probabilities. Thus, from the start, the general theses (1) were linked to close linguistic analysis involving both semantic and pragmatic considerations. One comes away from Lewis's papers with the sense that they could form the cornerstone for a successful (probabilistic) formal pragmatic theory.

The present paper investigates the pragmatics of evidential sentences in the general Lewisian terms (1). Now, evidential morphemes are rich and varied in their contributions, they might not form a natural class cross-linguistically (Matthewson et al. 2007:3, Speas 2007), and analyzing even a single morpheme generally proves complex (Davis et al. 2007, Fasola 2007). Thus, we do not, in this short paper, venture a comprehensive analysis. Rather, we focus on the pragmatic strategy that evidentials facilitate. Section 2 discusses the pragmatics of evidentiality. Section 3 carves out a role for probabilities in pragmatic theory, and Section 4 describes our analysis. We close the paper with a discussion of the connections between evidentiality and modality (Section 5 ) and a brief look at various promising extensions of these ideas (Section 6).

For helpful discussion, we thank Pranav Anand, Chris Barker, David Beaver, Rajesh Bhatt, Ariel Cohen, Carlos Fasola, Kai von Fintel, Jay Garfield, Edward Garrett, Angelika Kratzer, Eric McCready, Evangeline Parsons-Yazzie, Tom Roeper, Robert van Rooij, Scott Schwenter, Matt Tucker, Gregory Ward, and Malte Zimmermann. This material is based upon work supported by the National Science Foundation under Grant No. BCS-0642752 to Potts and Grant No. HSD-0527509 to Speas. Any opinions, findings, and conclusions or recommendations expressed in this material are those of the authors and do not necessarily reflect the views of the National Science Foundation.

${ }^{1}$ The two main papers are Lewis (1976) and Lewis (1980), each with its own lengthy postscripts. Similar ideas have been explored more recently by Merin (1997), van Rooy (2004), and McCready and Ogata (2007). 


\section{The Pragmatics of Evidentiality}

We are primarily concerned with evidential systems of the sort that Aikhenvald (2004) characterizes as grammaticized: closed class, generally unmodifiable, often obligatory, frequently bound morphemes. Thus, we largely set aside the evidentiality encoded in adverbial, parenthetical, and particle constructions. (For discussion, see Rooryck 2001a,b, Aikhenvald 2004, McCready and Ogata 2007, Speas 2007.) In (2), we provide some typical Tibetan examples, drawn from DeLancey (1986).
a. K'on gis yi-ge-bri-pa-soy.
s/he ERG write-PERF-DIRECT
'She wrote a letter (I saw it happen).'
b. K'on gis yi-ge-bri-pa-red.
s/he ERG write-PERF-INDIRECT
'She wrote a letter (it seems).'

The Tibetan direct/indirect contrast highlights what seems to be, in some sense, the most basic evidential contrast (Faller 2002b), though it should be emphasized that Tibetan has a much richer set of contrasts when we consider its full system of evidentiality.

Eastern Pomo makes a four-way distinction among evidence types (examples from McLendon 2003:101-102 and Aikhenvald 2004:52-53):
a. $\quad$ bi·Yá $\mathrm{p}^{\mathrm{h}} \mathrm{a} \cdot \mathrm{bé}-\mathrm{k}^{\mathrm{h}}$-ink'e hand burn-PUNCTUAL-SENSORY
'I burned my hand' (I feel the sensation of burning in my hand)
b. mí--p-al
$\mathrm{p}^{\mathrm{h}} \mathrm{a} \cdot \mathrm{bé}-\mathrm{k}-\underline{\mathrm{a}}$
3sg-male.PATIENT burn-PUNCTUAL-DIRECT
'He got burned' (I have direct evidence, e.g., I saw it happen)
c. bé·k-al $\mathrm{p}^{\mathrm{h}} \mathrm{a} \cdot \mathrm{bé}-\mathrm{k}$-ine
3pl-PATIENT burn-PUNCTUAL-INFERENTIAL
'They must have gotten burned' (I see circumstantial evidence — signs of fire, bandages, burn cream)

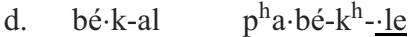
3pl-PATIENT burn-PUNCTUAL-REPORTED
'They got burned, they say' (I am reporting what I was told)

The glosses impart a sense for the nature of the evidentials' contributions, though translation is a fraught affair, as we discuss in Sections 2.6 and 4.3. But the important thing, for our purposes, is that evidential morphemes like these encode something about the speaker's source of evidence for the information being offered. We turn next to a closer look at this property. The subsections after that are inspired by clause (ii) of (1): they explore some central pragmatic properties of evidential sentences, concentrating on those that flow from the nature of the evidence source and the way in which it is signaled linguistically. 


\subsection{Evidence Sources}

Evidential sentences have multifaceted meanings-in-context, and this makes them of vital interest to researchers exploring all kinds of multidimensionality, including those that derive from presupposition accommodation (Sauerland and Schenner 2007), conventional implicature (Potts 2005), and illocutionary force. In this paper, we do not take a stand on the nature of these meanings. Rather, we highlight the meaning component that seems to derive most directly from the presence of the evidential morpheme: a speaker commitment to the existence of a situation of a certain type.

For instance, in the Eastern Pomo example (3b), the speaker commits himself to having direct evidence for the propositional content. In (3d), he commits himself to having heard a report of the propositional content. And so forth. The information is generally not very specific: the source of hearsay information must be recovered from the utterance context, for instance, since the evidential itself is atomic and unmodifiable. Roughly speaking, then, the speaker commitments are of the general form in (4), in which $S[\mathbf{e v}]$ is a declarative sentence containing an evidential morpheme and $\llbracket \cdot \rrbracket$ maps syntactic constituents to their meanings.

(4) Uttering $S[\mathbf{e v}]$ commits the speaker to the existence of a situation in which he receives ev-type evidence for $\llbracket S \rrbracket$.

There is a persistent intuition that these morphemes form a hierarchy based on an abstract notion of strength that relates intimately to evidence types. We turn now to this issue.

\subsection{Evidential Hierarchies}

Cross-linguistically, grammaticized evidential morphemes fall into one of just a handful of categories: personal experience, direct perception, hearsay, inferential, conjectural, and a few others (Willett 1988, Speas 2004). Different languages choose different subsets of the full set of evidential categories, and there is also considerable variation concerning how the morpheme types relate to specific information. But, as Speas (2004) observes, it is striking that so few of the conceivable types are realized.

We aim to model the pragmatic fact that some evidential morphemes are perceived to be stronger than others, and that this can, in turn, impact perceptions about the speaker's commitment to the main-clause content. One approach would be to place them into a conventional hierarchy, along the lines of the pragmatic scales often used for scalar inference (Fauconnier 1975, Horn 1989, Levinson 2000, Sauerland 2004). The following basic hierarchy is drawn from Willett (1988:57):

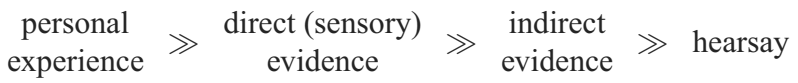

This makes intuitive sense. In our world (given our metaphysics), personal information is privileged. I (and only I) can say with absolute certainty whether I am 
in pain, or anxious, or dislike the taste of cauliflower. And given the nature of our world and our senses, direct information (visual, auditory, etc.) is extremely reliable, though we are more inclined to leave room for doubt given such evidence than we are for personal experience. Lower down on the hierarchy, the evidence becomes much less reliable. People pass on mistaken information, messages get garbled in transmission, and our inferences from indirect evidence can be openly full of holes. Thus, scales of the form in (5) seem grounded in extra-linguistic factors, so it is not surprising that the scales for individual languages tend to have its basic shape. Some examples drawn from Faller (2002b):

a. $\quad$ visual $\gg$ nonvisual $\gg$ apparent $\gg$ secondhand $\gg$ assumed

(Tuyuca; Barnes 1984)

b. $\quad$ performative $\gg \begin{gathered}\text { factual- } \\ \text { visual }\end{gathered} \gg$ auditory $\gg$ inferential $\gg$ quotative

(Kashaya; de Haan 1998)

With allowances for languages dividing up the space differently, this looks basically in keeping with (5). However, Faller (2002b) argues convincingly that hierarchies of the form in (5) and (6) are problematic. She reaches two general conclusions about evidential hierarchies: (i) they should order evidence types, not evidential morphemes; and (ii) they should be partial orders, with perhaps an abundance of incomparable elements. We would like to emphasize also that (iii) the hierarchies are subject to contextual variation (it is clear that Faller is thinking along these lines as well; see especially §3.2). Hearsay evidence can be uncertain in one context and solid in another. Inference is air-tight in some contexts but held to be loose in others. And so forth. This suggests that the hierarchy is genuinely pragmatic, i.e., not something that we can conventionalize completely. In Section 4.1, we attempt to make good on these three insights about the nature of evidential hierarchies.

\subsection{Readings in Interrogatives}

In the light of the above emphasis on speaker commitments, it is striking that evidentials are possible in interrogative sentences. However, when they appear in such clauses, they are often partly forward looking: their semantic contribution can impact both the question and the range of expected replies. We illustrate in (7) with an example from Tibetan, along with Garrett's (2001) insight about its contribution.

bkra.shis za.khang-la phyin-song-ngas

Tashi restaurant go-DIR.PAST-Q-EVIDENTIAL

'Did Tashi go to the restaurant?'

"presupposes that the hearer has direct evidence that Tashi has either gone or not gone to the restaurant, and expects [the hearer] to answer on such an evidential basis" (Garrett 2001:229)

Similar data are reported in Faller (2002a:§6.3.2) for Cuzco Quechua: 
Pi-ta- $\underline{n} \quad$ Inés-qa watuku-rqa-n?

who-ACC-EVIDENTIAL Inés-TOP visit-PST 1-3

'Who did Inés visit?'

i. speaker has best possible grounds for asking

ii. speaker expects hearer to base his or her answer on best possible grounds

If these assessments are correct, then the contribution of the evidential to an interrogative is rather more pragmatic than one might expect. It seems that the evidential does not modify answers-as-propositions, but rather answers-as-assertions, which might initially suggest a performative semantics for interrogatives (for discussion, see Karttunen 1977, Ginzburg and Sag 2001, Garrett 2001).

But the plot thickens. If we take seriously the characterizations in (7)-(8), then the interrogative's evidential can also target the question itself - its presuppositions and grounds for felicitous use. So the contribution is rather diffuse. This suggests that we cannot exclusively build the evidential in as a presupposition of the question, nor will it work to make it part of the propositional content of the elements that make up its content. The contribution is genuinely pragmatic in the sense that it seems to be about the utterance context, rather than the meaning of any particular utterance.

Before closing this section, we stress that the above examples do not represent the only attested function of evidentials in interrogatives. There is evidence that, cross-linguistically, they sometimes target only the presuppositions of the sentence, that they can function in a quotative fashion (Faller 2002a:233), and that they are occasionally coaxed into entirely new meanings in these contexts. These phenomena are in need of further investigation. However, for the theoretical ideas we offer below, it is important only that readings like those described above are attested for some uses of some morphemes in some languages.

\subsection{Asserted?}

There is a great deal of variation on the question of whether evidential-marked declaratives can or must assert their propositional content, particularly when the evidential is conjectural, hearsay, or inferential. The general verdict of Oswalt (1986) is that evidential declaratives are asserted and that evidential morphemes do not encode a reduced degree of certainty (see also Aikhenvald 2004). For Kashaya:

It might be noted that, despite the hierarchy, all propositions with the Kashaya evidentials are presented by the speaker as being certain and true.

(Oswalt 1986:43)

Some authors dissent from this position for certain morphemes. For discussion, see Faller (2002a), Matthewson et al. (2007), Sauerland and Schenner (2007), Fasola (2007). The account we develop below is able to make sense of these conflicting judgments. 


\subsection{Strengthening}

It's a striking feature of evidentials that they can be perceived as strengthening the overall assertive force of a declarative utterance. The strengthening generally occurs with direct and personal experience evidentials. Cuzco Quechua provides a useful illustration, since it is a language in which evidential marking is often optional, and hence we can fairly freely compare $S$ and $S$ [direct]. Faller (2002a) characterizes this shift in pragmatic terms:

The difference $[\ldots]$ is felt by consultants to be one of emphasis such that [a sentence with the direct evidential] is stronger than [one with no evidential].

(Faller 2002a:23)

This possibility has important implications for how we situate evidentials with respect to related operators. We address this question for modals in Section 5 below and for utterance modifiers in our conclusion (Section 6).

\subsection{Descriptive Ineffability}

It is hard to say what evidentials mean - hard to translate them, and hard to paraphrase them with other words of the same language. Faller (2002a) offers a general characterization (see also Rooryck 2001a:126):

Evidentials are notoriously difficult to translate, and translations into English tend to suggest that the evidential meaning does not contribute to the proposition expressed.

(Faller 2002a:23)

The issue arises not only for translation into languages that lack evidentials, but also for translation into languages that have them, as the range of uses can differ subtly or dramatically from one language to the next (Faller 2002b and Section 2.2). In their descriptive ineffability (and arguably in other ways as well), evidentials seem intimately related to expressive content items (Potts 2007).

\section{Subjective Probabilities and Lewisian Quality}

The previous section explored evidential sentences in the terms suggested by (1ii). The present section focuses on clause (1iii), which defines a role for probabilities in pragmatic investigation. Section 3.1 provides the general definitions and relates them to the usual intensional models for linguistics. Section 3.2 then applies those notions to a version of the maxim of quality. These general probabilistic notions and our view of quality are both central to the theory of evidentials developed in Section 4. 


\subsection{Subjective Probabilities}

Intensional models supply us with at least three ways to model an agent's belief state: as a set of propositions, as a single proposition (a region of logical space), and as a subjective probability distribution. In this paper, we use probability distributions to gain a pragmatic perspective on propositional content in general and epistemic states in particular:

A probability distribution for a countable set $W$ is a function $P^{W}$ from subsets of $W$ into real numbers in the interval $[0,1]$ obeying the conditions: (i) $P^{W}(W)=1$; (ii) $P^{W}(\{w\}) \geqslant 0$ for all $w \in W$; and (iii) if $p$ and $q$ are disjoint subsets of $W$, then $P^{W}(p \cup q)=P^{W}(p)+P^{W}(q)$. (We henceforth suppress the superscript $W$.)

These distributions support analogues of the usual operations on propositions: complementation, intersection, and the concepts defined in terms of them. One can also bring them closely in line with propositions (and epistemic states) in the usual sense (Merin 1997, Potts 2006). Following Lewis (1986a:§5), we use them primarily to model agents" epistemic states: subjective probability as "the measure of reasonable partial belief" (Lewis 1980:83). To do this, we take as basic a proposition Dox D $_{A, c}$ representing the epistemic state of agent $A$ in context $c$. We then conditionalize a uniform distribution, as in (10), to define a function $C_{A, c}$ ( $C$ for 'credence') that maps any proposition $p$ to $A$ 's degree of belief in $p$ in context $c$, as in (11).

(10) Let $P(-\mid p)$ be the function that maps any proposition $q$ to

$$
P(q \mid p) \stackrel{\text { def }}{=} \frac{P(q \cap p)}{P(p)} \quad \text { (undefined if } P(p)=0 \text { ) }
$$

where $P$ is a probability distribution. That is, $P(-\mid p)$ maps propositions to their conditional probabilities (for $P$ ) given $p$.

(11) The subjective probability distribution for an agent $A$ in context $c$ :

$$
C_{A, c} \stackrel{\text { def }}{=} P\left(-\mid \operatorname{Dox}_{A, c}\right)
$$

in which $P$ is a uniform distribution over $W$, i.e., $P(\{w\})=\frac{1}{|W|}$ for all $w \in$ $W$.

The examples in (12) suggest the ways in which $C_{A, c}$ models facts about $A$ 's belief state:

$$
\begin{array}{ll}
\text { a. } & C_{A, c}(p)=1 \\
\text { b. } & C_{A, c}(p)=.5 \\
\text { c. } & C_{A, c}(p)=.98 \\
\text { d. } & C_{A, c}(p)=0
\end{array}
$$

$A$ fully believes $p$ $A$ is unbiased about $p$ $A$ strongly suspects $p$ $A$ disbelieves $p$

We make extensive use of the space between the extremes (12a) and (12d). For more on the role that such distributions might play in semantics and pragmatics, see Lewis (1986a: 55,7), Merin (1997), van Rooy (2004), McCready and Ogata (2007), Parikh (2001). 


\subsection{Quality}

Grice's (1975) original notion of quality is demanding in terms of its call for knowledge and evidence:

(13) Gricean quality "Contribute only what you know to be true. Do not say false things. Do not say things for which you lack evidence."

(Grice 1975)

Lewis (1976) suggests a less stringent pressure of roughly the same kind:

(14) Lewisian quality "The truthful speaker wants not to assert falsehoods, wherefore he is willing to assert only what he takes to be very probably true. He deems it permissible to assert that $A$ only if $P(A)$ is sufficiently close to 1 , where $P$ is the probability function that represents his system of degrees of belief at the time. Assertability goes by subjective probability." (Lewis 1976:133)

We work exclusively with this Lewisian version of quality. Moving to the Gricean view would likely require a more complex metalogical interpretation of subjective probability distributions. This might be correct, but the belief-based Lewisian view seems better suited to our current application.

Both speakers and hearers feel the pressures of quality. For the speaker, it is a cap on what he can felicitously say, no matter how great the pressures of informativity may be. For the hearer, it is a sort of guarantee that the speaker intends to be trustworthy. Pragmatic enrichment based on quality is pervasive. For instance, if you ask me where Sam is and I reply, "I saw him in the library earlier", I don't completely answer your question. If you know me to be forthcoming, you will balance quality against the other pressures to determine that I am not sure where Sam is at present. After all, I provided less information than you asked for, so it must be quality that prevents me from venturing a complete answer. If freed from the constraints of quality, I might simply guess for the sake of providing a complete answer, and communication would rapidly break down. Quality is arguably the most fundamental of the pragmatic pressures.

Lewis's (14) is essentially a formal view of the quality pressure. For our analysis, we require just one additional concept: quality thresholds (Potts 2006), as defined in (15).

(15) Every context $c$ has a quality threshold $c_{\tau} \in[0,1]$.

And now we come to our formalization of Lewisian quality: ${ }^{2}$

(16) An agent $A$ can felicitously assert $p$ in context $c$ only if $C_{A, c}(p) \geqslant c_{\tau}$.

\footnotetext{
${ }^{2}$ This is a slight departure from the formulation in Potts (2006), in which $\geqslant$ is $>$. The earlier formulation militates against thresholds of 1 , whereas we think it is better to assume that this extreme case cannot arise due to general facts about our epistemic limitations, rather than as a result of the pragmatic theory.
} 
This corresponds roughly to the first clause of Grice's quality ("Contribute only what you know to be true."), and it seems a straightforward interpretation of Lewis's general statement about assertability (14).

Quality thresholds tend to be above .98 absent other indicators of their position. It is often assumed that the threshold is always 1, i.e., that complete belief is required for felicitous assertion (Büring 1998, de Jager and van Rooij 2007). Potts (2006) presents evidence that this is too stringent, and the data and observations in Taranto (2003) and Barker (2007) seem to support that view as well. In general, if we are honest with ourselves, we nearly always fall short of $100 \%$ certainty. This doesn't keep us silent, though. The flexible view of quality in (16) makes sense of this by allowing room for doubt.

\section{The Evidential Strategy}

We turn now to our theory of the pragmatics of evidential sentences. The theory is based in the view that an evidential sentence actively changes the context of utterance. In this sense, the theory defines evidentials as illocutionary force operators (Faller 2002a). (We think it also makes good on the intuition that evidentials are related to modals, but we defer that discussion to Section 5). At the heart of our proposal is the idea that evidentials mark a particular sort of speaker strategy: in using an evidential, the speaker triggers a context comparison of a particular sort.

In this section, we first link evidential morphemes to a particular kind of subjective probability (Section 4.1), and then we use those values to articulate the evidential strategy (Section 4.2).

\subsection{Probabilities and Evidential Morphemes}

We noted above that evidential sentences carry a speaker commitment to the existence of a situation of a certain type, as in (4), repeated here:

(17) Uttering $S[\mathbf{e v}]$ commits the speaker to the existence of a situation in which he receives ev-type evidence for $\llbracket S \rrbracket$.

The nature of these situations is vital to understanding the pragmatic strength of evidential sentences. Consider a situation $s$ in which someone receives hearsay evidence for a proposition $p$. The conditional probability, given the common ground, that $s$ is a situation in which $p$ is true might be very low. After all, people report all kinds of crazy things, and woe to the trusting individual who believes all of them. In contrast, a situation in which someone receives direct (e.g., visual) evidence for $p$ is almost always a situation in which $p$ is true. The probability tends to be much higher. It is higher still for the personal experience (ego) situations that are involved in evidential sentences like the Eastern Pomo example (3a).

The above characterizations are inherently probabilistic. They ask, What is the probability, given some assumptions, that this situation entails some particular 
piece of content? To model this, we proceed much as we did in Section 3.1 above. We first define a class of contextually-conditioned probability distributions:

(18) The subjective probability distribution for context $c$ :

$$
P_{c} \stackrel{\text { def }}{=} P\left(-\mid c_{C G}\right)
$$

where $P$ is a uniform distribution over $W$ and $c_{C G} \subseteq W$ is the common ground for the discourse participants of $c$.

We believe that functions like $P_{c}$ have a general role to play in pragmatic theory, but we have just one application in mind: we aim to capture the above intuitions about the contextually-determined strength of evidence sources. For this, we define, in (19), a function that associates evidential morphemes with probabilities.

(19) Let $\varphi_{\mathbf{e v}}$ be the proposition that a situation in which an agent obtains ev-type evidence for $p$ is also a situation in which $p$ is true.

$\mu$ maps context-morpheme pairs to probabilities:

$$
\mu_{c}(\mathbf{e v}) \stackrel{\text { def }}{=} P_{c}\left(\varphi_{\mathbf{e v}}\right)
$$

In most realistic contexts $c$, direct evidence is stronger than hearsay evidence, so we might have $\mu_{c}$ (direct $)=.98$ and $\mu_{c}$ (hearsay $)=.75$. However, in (perhaps farfetched) contexts $c$ in which direct perception is unreliable but speakers are scrupulous about passing on information only after it has been verified up to epistemic limits, $\mu_{c}$ (hearsay) might be higher than $\mu_{c}$ (direct).

The contextual dependency of this function is an important factor. If the speaker is known to hallucinate, then his direct perception evidentials might not carry much weight. Conversely, if the hearsay report is known to be from a reliable source, then it might be perceived as highly trustworthy, perhaps even trumping direct perception. Thus, it is important that we conditionalize the general distribution for each context, so that common-ground entailments are taken into account.

We are still dealing with subjective probabilities, rather than chance or frequency (Lewis 1980). Imagine some small children who trust reports from their parents more than their own eyes, so that "Mom says ...!" can signal the highest form of evidence possible for them (Tom Roeper, p.c.). These children are mistaken about the veracity of their parents' claims, but this objective fact is not what determines relative evidential strength. Rather, their common ground is the primary factor in determining $\mu_{c}$ and, in turn, the contextual hierarchy. The values obtained by $\mu_{c}$ are objective only insofar as they reflect a general understanding of the discourse participants in $c$. They might, though, be very different from actual chances or frequencies.

This approach provides a ready explanation for the fact that evidential hierarchies are hard to pin down (Section 2.2). Though direct evidence might be reliably better than hearsay evidence, this is not a lexical fact per se, but rather a fact that we derive from general regularities in the world and the context of utterance, and 
thus it is conceivable that things could be reversed in some situations. It is also easy to see why conjectural and hearsay evidentials might be impossible to order absolutely - these two kinds of evidence can be reliable or unreliable, depending on the circumstances. But we do furnish a (context-dependent) partial ordering, and thus standard scalar reasoning (of a particularized sort) is generally possible for sentences involving these morphemes. In our view, the ordering based on $\mu$ makes good on Faller's (2002b) insight that evidential hierarchies are best given in terms of evidence types rather than morphemes. We order morphemes, but we do it in a way that is keyed directly into evidence types (in context).

\subsection{The Strategy}

The theory itself is easy to state. Recall from Section 3.2 that every context $c$ has an associated quality threshold $c_{\tau}$. These thresholds are numbers in the unit interval, and an agent $A$ can felicitously assert $p$ only if $C_{A, c}(p) \geqslant c_{\tau}$, as in (16). So the threshold is a lower-bound on felicitous assertion.

Sincerely uttering a declarative evidential sentence of the form $S[\mathbf{e v}]$ is an assertion of $\llbracket S \rrbracket$, and thus the threshold is in force even for these sentences; the felicity of such an utterance by agent $A$ is determined in part by $C_{A, c}(\llbracket S \rrbracket)$. This would seem to be a problem, since ev might be a very weak evidential — say, conjectural - and thus it might actually indicate that the speaker is well below the threshold for $\llbracket S \rrbracket$. This is where we make our substantive theoretical move: we argue that the function of the evidential is to (potentially) change the contextual threshold, from whatever it was to the value given by $\mu_{c}(\mathbf{e v})$. The old threshold is replaced with a (potentially) new one derived from the common ground and geared towards furnishing a reliability indicator. This theory is summarized in (20).

If $S[\mathbf{e v}]$ is uttered by agent $A$ in context $c$, then

i. $A$ assumes a commitment to having ev-type evidence for $\llbracket S \rrbracket$.

ii. $c_{\tau}$ becomes $\mu_{c}(\mathbf{e v})$, and then

iii. $A$ performs a speech-act with $\llbracket S \rrbracket$ (probably an assertion if $S$ is a declarative, probably a question if $S$ is interrogative, etc.).

It is crucial that the threshold changes before the speech act of (20iii). In regular declarative sentences, the speaker's pragmatic strategy with the evidential is to shift the threshold to a point at which the assertion respects quality, (16). And we capture this: $A$ 's assertion of $\llbracket S \rrbracket$ is judged pragmatically in this new context (i.e., relative to the new $c_{\tau}$ ).

Our focus is the interaction between (20ii) and (20iii), but the speaker commitment (20i) is the primary lexical contribution, so we cannot simply ignore it. We therefore offer a few brief remarks.

First, it seems important that (20i) comes before the change to the threshold. The content might best be thought of as a (very easily accommodated) presupposition, or we could venture a more clearly multidimensional analysis. Unfortunately, we don't have the space to explore this issue here. 
Second, more work needs to be done in exploring the influence of syntactic position on (20i). Here, the interrogative data of Section 2.3 should play a major role. Embedded contexts are also challenging. Such readings are a focus of Sauerland and Schenner (2007), who look primarily at Bulgarian evidentials. (For additional discussion of both issues, see Garrett 2001:\$5,6.) Again, we cannot explore this issue here, so we must simply emphasize that the nature of this contribution is relatively independent, as far as we can see, from our proposal, which mainly concerns the interplay between the change to the threshold, (20ii), and the utterances that follow it. (For declaratives, the next content evaluated is the main descriptive content, as in (20iii).)

The shift to the threshold (20ii) has a hallmark of presuppositionality, since it happens before the assertion. But we prefer not to think of this step as imposing definedness conditions - though, of course, its action can lead to pragmatic anomaly for the content to come. That is, it is possible for an assertion to be infelicitous before the evidential does its work but felicitous after. This will be the norm for evidentials whose $\mu$-values are low. And the threshold shift can, if it raises the previous value, make an utterance that would have been felicitous before the shift into one that is infelicitous.

\subsection{Summary of Results}

The context-shifting specified in (20) might seem unusual, but it derives the full range of pragmatic phenomena discussed in Section 2.

Evidential Hierarchies (Section 2.2) Their variability follows from the fact that evidential morphemes are ordered by the values of $\mu$, which can vary from context to context.

Readings in Interrogatives (Section 2.3) The initial puzzle is that evidentials can appear in interrogatives at all, despite their orientation towards speaker evidence. But their contributions in such environments turn out to be revealing. The evidential is wide-ranging, in a sense. It seems not to be exclusively about the content of the question and its preconditions, nor is it clearly about the replies. Both aspects of the utterance seem to be targeted, as we see in (7) and (8). On our account, this diffusion is entirely expected. The pragmatic function of the evidential is to shift the context before the primary speech-act itself takes place. And we assume that the threshold remains in its new position until new evidential morphology (or some other pressure) changes it again. Thus, both the interrogative and any utterances that follow feel the effects of the change described in (20ii).

Could more narrowly semantic accounts, say, those based on notions of presupposition and modality, capture this indirect and long-distance effect on the meanings and, in turn, on the discourse structure? We think they could. They could do this by appeal to the pragmatic expectations generated indirectly by the meanings involved. We wish to emphasize that this is precisely what we are up to. 
We have simply been very precise about how speaker expectations can work in this way to shape a discourse.

Mixed Judgments about Assertion (Section 2.4) On our analysis, evidential-marked declaratives are asserted, as is evident from (20iii). However, this assertion might well be happening in a context in which the contextual threshold has been lowered considerably. This is almost guaranteed to lead the hearer to perform comparative inferences of the following form: the assertion was not made in a stricter context, or a more normal one, and, as a result, its overall contribution is greatly weakened as well. We depict this reasoning informally in (21).

(21) The speaker did this, not this.

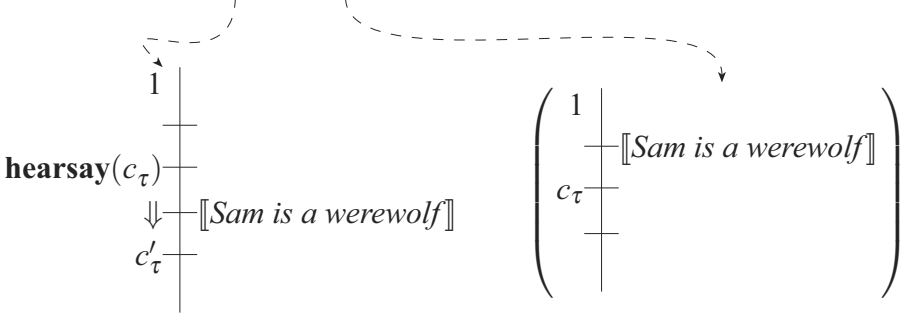

Evidential sentences present a second challenge for determining whether the declaratives containing them are asserted. Their pragmatic values are very tightly connected to their form, so much so that these values might count as intrusive (Levinson 2000, Chierchia 2004). If we are right about the role of probabilities, then speakers might therefore have a difficult time with the truth-value judgments that go along with gauging assertions. Probabilities do not naturally support this sort of boolean reasoning (Kamp and Partee 1995). As theorists, we can appeal to the semantics for such relations, but speakers' intuitions probably don't reliably tease this information apart from lexically-encoded probabilistic pragmatics.

Strengthening (Section 2.5) Moving the threshold up is as easy as moving it down. We therefore expect this symmetry in evidential types. The real factor here is the range of evidence that the morphological system allows speakers to connect with.

Descriptive Ineffability (Section 2.6) These difficulties of translation make sense on our account. For us, evidentials do not denote propositions, nor do they directly quantify over sets of propositions. They change the context in a highly contextdependent way. If a language $L$ lacks evidentials, then epistemic modals or parentheticals might provide the best rough-and-ready translation in $L$ for evidential morphemes, but these translations might fall short when it comes to reproducing the effects of (20). 


\section{Modality and Evidentiality}

There is not space for detailed argumentation here, but it is worth briefly describing how our account of evidentials might reveal both how they are related to epistemic modals and also how the two can differ.

On the account summarized in (20), the quality threshold is actively changed by the morphology. We suggest a more conservative characterization of the modal strategy: here, the threshold remains fixed, but the addressee is implicitly invited to compare two utterances: the modalized statement he heard and the unmodalized statement that the speaker chose not to use. This utterance choice will likely convey that the speaker is in the situation depicted in (22), in which $S$ is off-limits, by quality, but the modalized versions are pragmatically accessible.

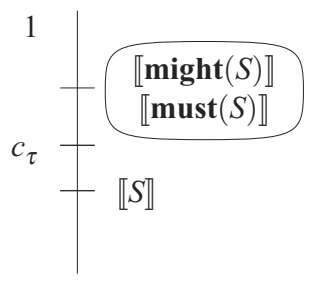

It is nearly always the case that $\operatorname{might}(S)$ is perceived as weaker than $S$. This is also a strong tendency for necessity modals, but it is not exceptionless for them. Building on insights of Karttunen (1972), von Fintel and Gillies (2007), present convincing evidence that some uses of epistemic must are not weaker than their unmodalized counterparts. They argue that the modal signals a conclusion based on inference or deduction. In formal proofs, such inferences can be as solid as direct evidence, but they are perceived as weaker than direct evidence in normal conversational circumstances, where we recognize that the entailments of the context might not be valid in reality. What's more, Birner et al. (2007) observe that certain epistemic uses of would (as in That would be Chris, upon hearing a knock at the door at his expected arrival time) mark "the speaker's high level of confidence in the truth of the proposition" (p. 320) and are, in fact, reliably perceived as stronger than regular assertions (p. 320, footnote 2). Thus, in general, we might allow that an epistemic modal can indicate something like the following: even if the threshold were raised, the content would still be accessible, which conversationally implicates increased speaker commitment.

So the central difference, we propose, is that the modal can't change the threshold, whereas the evidential can. We should take care not to let this overshadow an important connection between the two expression types that traces to the role of subjective probabilities. On our account, both the evidential and modal strategies are likely to be fueled by the same fact about the epistemic state of the speaker: if $p$ is the propositional content of the utterance, then $C_{A, c}(p)<c_{\tau}$. In a language with epistemic modals and evidentials, a speaker can say something about $p$ despite $C_{A, c}(p)$ either by qualifying it with a modal or by using an evidential to change the current standard for assertability $c_{\tau}$. (Her choice is likely to be governed 
by the question of whether the evidence source is relevant at that point in the discourse and, presumably, whether any epistemic modals encode such information.)

This is an abstract connection, and that is arguably a virtue. After all, there is little evidence that epistemic modals are related historically to modals (they derive more commonly from aspectual markers and attitude predicates), and there is no general consensus on the question of how deeply the relationship between these two classes runs. For a range of opinions, see Matthewson et al. (2007), Donabédian (2001), Faller (2002a,b), von Fintel and Gillies (2007), Garrett (2001), Plungian (2001). ${ }^{3}$

\section{Summing up and Looking Ahead}

Building on the probabilistic foundation laid by Lewis (1986a:§5), we characterized the pragmatic strategy that evidentials embody. The characterization involves a particular kind of context shifting (one that resembles that employed for expressives in Potts (2007). As discussed in Section 4.3, it provides an immediate account of a range of pragmatic features of evidential sentences (Section 2). It seems to set up a fruitful connection with epistemic modality (Section 5), and its dependence on context-shifting arguably does justice to the intuition that evidentials are illocutionary force operators.

We close this paper by suggesting that the account might be applicable to utterance modifying adverbs and parentheticals - that it might, in particular, yield insights into the hierarchy in (23), in which the degree to which it is asserted that Ed is a werewolf seems to drop as we move from top to bottom.

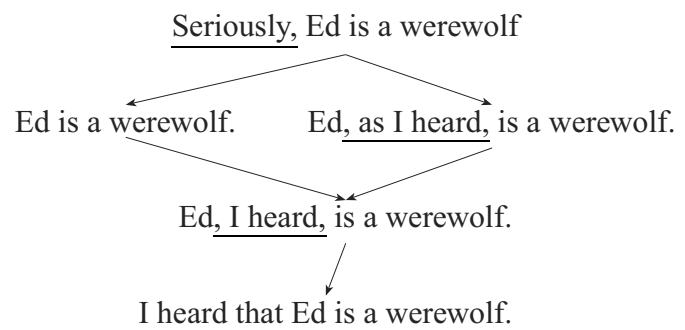

Ross's (1973) slifting construction ( $E d$, I heard, ...) is of particular interest. Like evidentials, slifts yield mixed judgments about whether the content is asserted or not. And, like evidentials, they encode something about the speaker's source of evidence for that main-clause content, though with much greater syntactic and semantic freedom than is found with evidential morphemes.

In our terms, slifts lower the threshold. Many utterance modifying adverbs raise the quality threshold. This seems to be the primary contribution of honestly

\footnotetext{
${ }^{3}$ We leave open the question of whether an epistemic modal might acquire an evidence-type commitment and a context-shifting interpretation, thereby becoming semantically and pragmatically just like an evidential.
} 
and seriously when set off intonationally as in (24) (Bach and Harnish 1979).

a. Honestly, Ed is a werewolf.

b. Seriously, we need to get to work on the paper.

These do not have accurate paraphrases with verb-phrase adverbs or adjectives, nor do they embed easily (if at all; Bach 1999). Rather, they seem to function solely to strengthen speaker commitments. Strikingly, utterance modifiers can appear with a wide range of complements (Seriously, go home; Honestly, is Ed a werewolf?), a further parallel with evidentials (see Section 2.3). Faller (2002a:237-238) makes the connection explicit, noting that both evidentials and utterance modifiers "are anchored to the hearer in content questions". Thus, though grammaticized evidentials might form their own linguistic class to the exclusion of parentheticals and adverbials, paying serious attention to (probabilistic) pragmatic values might furnish the right level of abstraction for capturing the commonalities among them.

\section{References}

Aikhenvald, Alexandra Y: 2004, Evidentiality. Oxford University Press, Oxford.

Bach, Kent: 1999, 'The Myth of Conventional Implicature', Linguistics and Philosophy 22, 367-421.

Bach, Kent and Robert M. Harnish: 1979, Linguistic Communication and Speech Acts. MIT Press, Cambridge, MA.

Barker, Chris: 2007, 'Clarity and the Grammar of Skepticism'. Ms., NYU.

Barnes, Janet: 1984, 'Evidentials in the Tuyuca Verb', International Journal of American Linguistics 50, 255-271.

Birner, Betty, Jeffrey P. Kaplan, and Gregory Ward: 2007, 'Functional Compositionality and the Interaction of Discourse Constraints', Language 83, 317343.

Büring, Daniel: 1998, 'Identity, Modality, and the Candidate Behind the Wall', in D. Strolovich and A. Lawson (eds.), Proceedings from SALT 8, 36-54. CLC Publications, Ithaca, NY.

Chafe, Wallace and Johanna Nichols (eds.): 1986, Evidentiality: The Linguistic Coding of Epistemology. Ablex Publishing, Norwood, NJ.

Chierchia, Gennaro: 2004, 'Scalar Implicatures, Polarity Phenomena, and the Syntax/Pragmatics Interface', in A. Belletti (ed.), Structures and Beyond: The Cartography of Syntactic Structures, Vol. 3, 39-103. Oxford University Press, New York. [The manuscript began circulating in 2001].

Davis, Henry, Hotze Rullmann, and Lisa Matthewson: 2007, ' Out of Control' Marking as Circumstantial Modality in St'át'imcets'. Ms., UBC.

DeLancey, Scott: 1986, 'Evidentiality and Volitionality in Tibetan', In Chafe and Nichols (1986), 203-213.

Donabédian, Anaïd: 2001, 'Towards a Semasiological Account of Evidentials: An Enunciative Approach of -er in Modern Western Armenian', Journal of Pragmatics 33, 421-442. 
Faller, Martina: 2002a, Evidentiality in Cuzco Quechua, PhD dissertation, Stanford. Faller, Martina: 2002b, 'Remarks on Evidential Hierarchies', in D. Beaver, L. D. C. Martínez, B. Z. Clark, and S. Kaufmann (eds.), The Construction of Meaning, 89-111. CSLI, Stanford, CA.

Fasola, Carlos: 2007, 'A Unified Semantics for the Quechua Question and Negation Marker -Chu'. Paper presented at SULA 4, São Paulo, Brazil, May 25.

Fauconnier, Gilles: 1975, 'Pragmatic Scales and Logical Structure', Linguistic Inquiry 6, 353-375.

von Fintel, Kai and Anthony S. Gillies: 2007, 'An Opinionated Guide to Epistemic Modality'. To appear in T. Szabó Gendler and J. Hawthorne (eds.), Oxford Studies in Epistemology, Vol. 2. Oxford University Press.

Garrett, Edward John: 2001, Evidentiality and Assertion in Tibetan, $\mathrm{PhD}$ dissertation, UCLA.

Ginzburg, Jonathan and Ivan A. Sag: 2001, Interrogative Investigations: The Form, Meaning, and Use of English Interrogatives. CSLI, Stanford, CA.

Grice, H. Paul: 1975, 'Logic and Conversation', in P. Cole and J. Morgan (eds.), Syntax and Semantics, Vol. 3: Speech Acts, 43-58. Academic Press, New York.

de Haan, Ferdinand: 1998, 'The Cartegory of Evidentiality'. Ms., University of New Mexico.

Horn, Laurence R.: 1989, A Natural History of Negation. University of Chicago Press, Chicago. Reissued 2001 by CSLI.

de Jager, Tikitu and Robert van Rooij: 2007, 'Deriving Quantity Implicatures', in Proceedings of Theoretical Aspects of Rationality and Knowledge. ACM Digital Library, New York.

Kamp, Hans and Barbara H. Partee: 1995, 'Prototype Theory and Compositionality', Cognition 57, 129-191.

Karttunen, Lauri: 1972, 'Possible and Must', in J. P. Kimball (ed.), Syntax and Semantics, Vol. 1, 1-20. Academic Press, New York.

Karttunen, Lauri: 1977, 'Syntax and Semantics of Questions', Linguistics and Philosophy 1, 3-44.

Levinson, Stephen C.: 2000, Presumptive Meanings: The Theory of Generalized Conversational Implicature. MIT Press, Cambridge, MA.

Lewis, David: 1976, 'Probabilities of Conditionals and Conditional Probabilities', Philosophical Review 85, 297-315. Reprinted in Lewis 1986a, 133-156. Page references are to the reprinting.

Lewis, David: 1980, 'A Subjectivist's Guide to Objective Chance', in R. C. Jeffrey (ed.), Studies in Inductive Logic and Probability, Vol. 2. University of California Press. Reprinted in Lewis 1986a, 83-113. Page references are to the reprinting.

Lewis, David: 1986a, Philosophical Papers, Vol. 2. Oxford University Press, New York.

Lewis, David: 1986b, 'Postscript to 'Probabilities of Conditionals and Conditional Probabilities', In Lewis (1986a), 152-156.

Matthewson, Lisa, Henry Davis, and Hotze Rullmann: 2007, 'Evidentials as Epis- 
temic Modals: Evidence from St'át'imcets'. Ms., UBC.

McCready, Eric and Norry Ogata: 2007, 'Evidentiality, Modality, and Probability', Linguistics and Philosophy 30, 147-206.

McLendon, Sally: 2003, 'Evidentials in Eastern Pomo with a Comparative Survey of the Category in Other Pomoan Languages', in A. Y. Aikhenvald and R. M. W. Dixon (eds.), Studies in Evidentiality, 101-129. John Benjamins, Amsterdam.

Merin, Arthur: 1997, 'If All our Arguments had to be Conclusive, There Would be Few of Them', Arbeitspapiere SFB 340 101, University of Stuttgart, Stuttgart.

Oswalt, Robert L: 1986, 'The Evidential System of Kashaya', In Chafe and Nichols (1986), 29-45.

Parikh, Prashant: 2001, The Use of Language. CSLI, Stanford, CA.

Plungian, Victor: 2001, 'The Place of Evidentiality Within the Universal Grammatical Space', Journal of Pragmatics 33, 349-357.

Potts, Christopher: 2005, The Logic of Conventional Implicatures, Oxford Studies in Theoretical Linguistics. Oxford University Press, Oxford.

Potts, Christopher: 2006, 'Clausal Implicatures via General Pragmatic Pressures', in E. McCready (ed.), Proceedings of Logic and Engineering of Natural Language Semantics 2006. Japan Society for the Promotion of Science, Tokyo.

Potts, Christopher: 2007, 'The Expressive Dimension', Theoretical Linguistics 33, 165-197.

Rooryck, Johan: 2001a, 'Evidentiality, Part I', Glot International 5, 3-11.

Rooryck, Johan: 2001b, 'Evidentiality, Part II', Glot International 5, 161-168.

van Rooy, Robert: 2004, 'Relevance of Complex Sentences'. Ms., University of Amsterdam.

Ross, John Robert: 1973, 'Slifting', in M. Gross, M. Halle, and M.-P. Schützenberger (eds.), The Formal Analysis of Natural Languages, 133-169. Mouton de Gruyter, The Hague.

Sauerland, Uli: 2004, 'Scalar Implicatures in Complex Sentences', Linguistics and Philosophy 27, 367-391.

Sauerland, Uli and Mathias Schenner: 2007, 'Embedded Evidentials in Bulgarian', in E. Puig-Waldmüller (ed.), Proceedings of Sinn und Bedeutung 11, 525539. Universitat Pompeu Fabra, Barcelona.

Speas, Margaret: 2004, 'Logophoricity and the Syntactic Representation of Pragmatic Features', Lingua 114, 255-276.

Speas, Margaret: 2007, 'On the Syntax and Semantics of Evidentials'. To appear in The Linguistic Compass.

Taranto, Gina: 2003, Discourse Adjectives, PhD dissertation, UC San Diego.

Willett, Thomas: 1988, 'A Cross-Linguistic Survey of the Grammaticization of Evidentiality’, Studies in Language 12, 51-97. 